\title{
Using Google Maps road traffic estimations to unfold spatial and temporal inequalities of urban road congestion: A pilot study from Budapest
}

\author{
PÉter BAJI ${ }^{1}$
}

\begin{abstract}
In recent urban geography literature, smart cites became a fashionable subject. The smart city paradigm is strongly connected to researches based on big data. The main objective of this paper is to strengthen the idea of usefulness of big data in examining and developing the urban transportation system as part of smart cities. In this pilot research, Google Maps traffic estimation data were used to evaluate the special vehicular traffic flows in District 3, in Budapest. On 45 defined road sections, travel time estimation data were collected with the aim to calculate the extent of wasted time in traffic jams. According to our results this source of 'big data' is a feasible way of conducting 'smart' research on a city road system. The most relevant advantage of this database is that it is continually generated on a high spatial and temporal resolution. The conclusion of this pilot research is that spatial and temporal inequalities are evincible from this database, unrecognized processes can be easily analysed, which can help urban planners to rethink their strategies on urban transport system. The most important findings showed that, on workdays, there is a second wave of peak traffic on many roads, and, within our chosen district, there are congestion hot spot places. It is important to note that Google Maps data have limits, but by understanding them this method is a useful way for geographers to examine urban traffic congestion patterns with a high spatial resolution.
\end{abstract}

Keywords: smart city, urban transport, big data, Google Maps, travel costs, wasted time, urban traffic

\section{Introduction}

Over the last decade, smart cities became a fashionable subject of urban development both in the international academic literature and public discourse. There are three main global urban issues wherein the smart city concept can provide solutions for urban development. The first is urban crowd or congestion: cities should handle their growing population and the challenges that this process generates (ChuAn TAO, Y. et al. 2015). The second issue is providing sustainable urban environment in cities for a higher quality of life for their citizens (AbElla-Garcia, A. et al. 2015). The third issue is creating social inclusion and decreasing inequalities in ur- ban life conditions (BАTTY, M. et al. 2012). Big ICT companies like IBM, Cisco or Telekom provide IT solutions for cities who put their investments in 'smart city' development projects in order to promote their 'smart', 'sustainable' and 'green' nature. At the same time social researchers are more critical about these oversimplified computational solutions to social problems (АNттіRoiкo, A.V. 2013, 2014; Townsend, A.M. 2013; Kitchin, R. 2014).

The main objective of this paper is to strengthen the idea of usefulness of big data in examining and developing the urban transportation system. In 2011, Google Maps made its real-time traffic congestion data available in Hungary, and today they also have available traffic forecasts on cer-

\footnotetext{
${ }^{1}$ Institute for Sociology, Centre for Social Sciences, Hungarian Academy of Sciences, H-1097 Budapest, Tóth Kálmán u. 4. E-mail: baji.peter@tk.mta.hu
} 
tain roads where significant congestions can be measured. These data can provide lots of new insights for urban geographers especially in cities like Budapest, where vehicular traffic jams generate huge problems.

For the sake of this pilot research the $3^{\text {rd }}$ district of Budapest was chosen as case-study area due to several reasons. Firstly, this district lies in a geographically transitional position between the 'wealthier' north-western part of the suburban zone and the downtown area of Budapest; thus, vehicular traffic generated both by commuters and inner-city car users can be analysed at the same time. For instance, in recent times, the volume of commuters from agglomeration settlements to Budapest has increased (KESERú, I. 2013), and this extra traffic can be observed on the roads of the case-study district. Moreover, this area has mixed residential land use pattern, with the largest pre-fab housing estate in Budapest, garden suburbs, and high-density downtown-type urban housing. These differences can serve as explanatory factors for the road traffic patterns. Secondly, this area has a complex, but well analysable, road system that fits the organic historical neighbourhood types of the district; thus, it is suitable for a pilot study.

\section{Research background}

\section{Smart transport and mobility as a smart city 'domain'}

Since cities are complex systems containing lots of physical, social and environmental layers, smart city research also addresses different aspects (or so-called 'domains') of smart cities. According to MAtтoni, B. et al. (2015), there are hard and soft domains in smart city development. Hard domains are related to the physical infrastructures of the city, like energy grids, water management system, buildings, or transport. In the development of these domains, the relevance of big data generated by sensors and their software is often emphasized (Neirotti, P. et al. 2014). Among them smart urban transport is probably the most promising research field for geographers, because the optimization of an urban transport system directly improves the life of local residents and the environment of the city.

In the international literature, lots of studies emphasize the potential development possibilities of smart mobility or intelligent transport systems (GIFFInGER, R. et al. 2007; Атtiroiko, A.V. et al. 2014; Steenbruggen, J. et al. 2015; Bálint, D. and Trócsányi, A. 2016). During the development process of telecommunication in the 1990's, a demand arose among developers to keep track of urban traffic flows even in real-time (MARvin, S.J. 1994), and today, through smart sensors and contracted GPS user transporters, these flows became analysable (these results can be seen in a simplest way on Google Maps). These data are increasingly feasible for unfolding and detecting traffic jam zones within the city; furthermore, these real-time data provide opportunities for quick intervention for urban planners and a great potential for urban researchers to detect the results of these interventions. Thus, cities became "urban laboratories", where planners and researchers can conduct experiments (BATTY, M. et al. 2012).

This study is strongly connected to the old dilemma of interchangeability of the travelling and telecommunication (Graham, S. 1997); the main point of this issue is how society can decrease travel time, travel costs, and lower the level of pollution through cheaper telecommunication opportunities that connect people while eliminating the need to travel (e.g. home office days, Skype meetings). The importance of this issue was highlighted by a recent study based on the Hungarian time-budget survey (1986/19872009/2010), which revealed the consistency of the average daily transport time-use per capita (60-65 minutes) in the last four decades, and showed that in this period the motorcycle/car time-use ratio roughly doubled in the total transport time use among Hungarian commuters (FleISCHER, T. and TIR, M. 2016). 
Environmental, economic and social effects of urban congestion

It is also important to note that urban transport systems generate 40 per cent of carbondioxide emissions in modern cities, but there are good examples where this pollution has been decreased through smart IT solutions and cross-city cooperation (NAvarro, C. et al. 2015). In the last decades, a lot of studies have highlighted the increasing amount of air pollution caused by urban sprawl and road traffic congestion in different urban areas around the world (CHIN, A. 1996; CAMAGNi, R. et al. 2002; Quingyu, L. et al. 2007). Although, different vehicle types generate different amounts of pollutants, the emission ratio is higher in traffic jams, thus, congestion hot spots became pollution hot spots, too.

The economic and social effects of road traffic congestion can be measured by the length of vehicles' travel delay. On the one hand, researchers argue that measuring congestion with the help of travel delay times can show the amount of unproductive, wasted time for society (Cohen, H. and Southworth, F. 1999; Schrank, D. et al. 2010). On the other hand, it is not clear how the real value of time and an accurate benchmark of road congestion can be defined (Rouwendal, J. and Nijkamp, P. 2004; SweEt, M. 2011). Although, the economic costs of congestion are more measurable (e. g. by the amount of wasted work time), several studies highlight that these kinds of travel delays not always generate significant losses in economic productivity (STOPHER, P.R. 2004) because individuals change their travel behaviour through modal, temporal and spatial corrections (Downs, A. 1992).

\section{Big data applications for a better understanding} of the city

Based on the international smart city literature, it is safe to claim that the use of big data is unavoidable, because such data enable real-time analysis of city life and provide huge amounts of information for planners in order to make more sustainable and efficient cities (Kitchin, R. 2014). Kitchin, R. (2013, 2014) emphasizes that using big data for urban research can complement well-known 'small data' research like censuses and other smallsample based qualitative surveys. Because of the high accessing velocity (created at close to real time) and the high spatial and temporal resolution of this data type, it can provide static snapshots and overviews of the dynamic unfolding of the daily life pattern of cities.

Many researchers emphasize, furthermore, that data generated worldwide about society and business sectors are growing dynamically; moreover, today, more data is being generated every two days than in all of history (MANYika, J. et al. 2011; SMOlan, R. and Erwitt, J. 2012; Zikopoulos, P.C. et al. 2012; RiaL, N. 2013). Although growth of available data can be seen impressive for 'data hungry' researchers, it is important to note that there are several difficulties when we try to use these data sets. For instance, in most cases, big data come from a huge unstructured file with different types of data (numbers, pictures, strings), therefore, making reliable connections among these data can be a slow and complex work (Al NuAimi, E. et al. 2015).

According to Kitchin, R. (2014), the sources of big data can be divided into three categories: directed, automated, and volunteered. Directed data comes from the traditional forms of surveillance conducted by states (e.g. passport control, fingerprints, public surveillance cameras). Automated data are produced by automatized data capture systems like smart phones that record their usage history and cell phones' call data. The third type of data source is volunteered data, which is generated by the conscious decisions of users who make observations, and create posts and uploads on social media sites, for example (Lengyel, B. and Јакові, Á. 2016). While the first and third categories generate several concerns about defending personal privacy (NiARos, V. 2016), the second source can provide aggregated data without ethical problems. Research results presented in this paper are clearly linked with the second big data source. 


\section{Methods and database}

Transport sciences have a long history of measuring traffic flows with different methods and approaches (WARDROP, J.G. and Charlesworth, G. 1954; Leduc, G. 2008). Transportation engineers generate traffic data with the help of static and dynamic measurement methods. The typical way of measuring cross-sectional static traffic is by using loop detectors to calculate the number of vehicles passing through a given point of a road. For instance, the national cross-sectional study in Hungary uses raw data from this type of instrument (Magyar Közút Nonprofit Zrt. 2017). Although the advantage of this method is its accuracy, its main limit is the spatially fixed nature of the measuring instruments, therefore, the length and geographical positon of measured road sections are consistent. Thus, these data can be used for transportation planning on a larger geographical scale, but the local spatial pattern of transport habits in urban society cannot be detected this way. The other method for unfolding traffic flow patterns is dynamic measurement. Formerly, this method used a car moving with traffic and registering its own traits of trajectory. In recent times, FCD (Floating Car Data) measurement has been emerging: where vehicles operated by fleet management systems send their GPS data while they are in traffic. This real-time data is supplemented by private car owners' GPS positions, using navigation applications on their drivers' smart phones. Google Maps traffic data is typically generated this way; hence, in comparison with the aforementioned cross-sectional survey, the advantage of these data is in their temporal and spatial resolution. Moreover, annual Hungarian cross-sectional surveys are limited to main roads, and they cannot detect the traffic patterns in smaller urban roads within a day.

This pilot study tried to test the usefulness of big data about traffic generated by Google Maps. In the first step, the measured roads of the whole district were subdivided into roughly one-km-long sections. These sec- tions were adjusted according to the morphology of the district's urban road system, and I made sure to fit them to the real organic neighbourhoods. The total number of road sections is 45 . Secondly, I defined a week when traffic estimation data were collected. This time period was from 13 to 19 November 2017. Choosing a complete week helped me to observe the road traffic patterns on weekend days as well as workdays. The selected time period is a normal week without any national holiday; and in November the number of tourists is generally low. Thus, the estimated traffic data closely approaches the real average traffic in this time period.

The third step was the process of data collection with the help of Google Maps (www. maps.google.hu). From this website, two data types where collected: the basic travel time (shorter) and the travel time with the estimated traffic volume (longer). The time intervals of collected data within the days were 20 minutes long, because the website allowed this temporal level. The first point of time was 06:00 in the morning and the last was 22:00 at night on every measured day. After the raw data were collected, I built a database on further indicators, like average speed of traffic, total number of vehicles, and volume of time wasted per kilometre and car on certain road sections. To estimate the number of vehicles, the so-called Greenshields-formula was used (GREENSHIELDS, B.D. 1935), which assumes that there is a linear connection between the velocity and the density of road traffic. Even though this formula was developed for estimating highway traffic, which is simpler than urban road systems with their intersections and traffic lights, it is still applicable to the general estimation of urban traffic patterns as well (ERHART, Sz. 2007), and thus it is suitable for the main goal of this pilot research.

$$
V=V_{\max }\left(1-\frac{K}{K_{d}}\right),
$$

where $V=$ velocity, $V_{\max }=$ maximum velocity, $K=$ actual traffic density, $K_{d}=$ traffic density in the case of maximum traffic congestion; 


$$
Q=V \cdot K
$$

where $Q=$ number of vehicles in a certain time period on the defined road.

Using these indicators, I was able to compare the main temporal and spatial traffic patterns of the districts. Finally, the whole database was analysed with statistical methods and thematic maps were produced.

According to Google's official statements, these data are calculated using different sources: government departments of transportation, and private data providers (gadgets.ndtv.com). The latter include individuals who use smart phones for navigation (e.g. Waze or Google Maps). Although Google has enough collected historical data even in Budapest to make rather accurate real-time and future traffic estimations, the accuracy of data always depends on the actual number of 'data providers' within the chosen area. However, the data on these numbers are not public. Even though Google Maps traffic estimations have been used for many years in different countries, little scientific analysis has been conducted about the accuracy of their application; but there is some evidence about the fairly good accuracy of web-based traffic estimations like those done with Google Maps (Morgul, E. et al. 2014).

\section{Results of the pilot research}

\section{The big picture: basic pattern of daily road traffic}

According to the results, there are three different daily congestion flow types within a week, if we analyse the cumulated data in the whole district. The first type is the typical workday from Monday to Thursday. On these days we can differentiate three main congestion time periods (Figure 1).

In the direction of the city centre roads become congested in two waves. In the morning, this wave lasts from 6.00 to 11.20 , with the peak between 7.40 and 8.00 . Though the volume of traffic decreases around midday, it does not fade away. The second wave starts

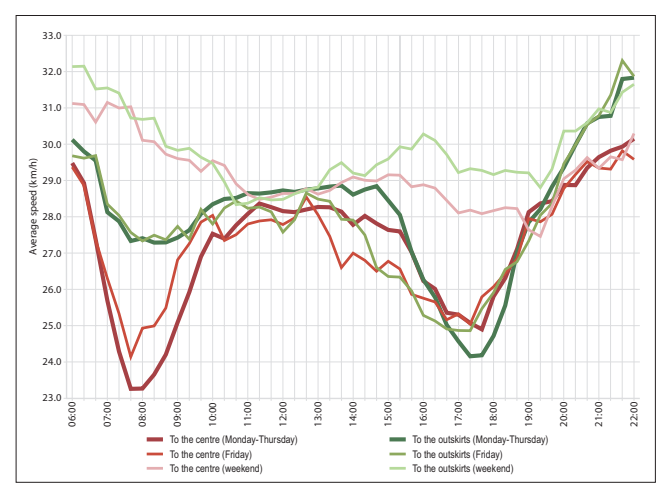

Fig. 1. Estimated average traffic speed on measured roads of District 3 in Budapest over a day. Time of estimation: 13.11.2017-19.11.2017. Source: https://maps.google.com

in the afternoon from 14.20 and ends at night 20.20. This wave peaks at 17.40. Comparing the two traffic waves in the direction of the city centre, we can see that the morning one is larger in volume. But observing the second wave points to a frequently unrecognized phenomenon which, in terms of urban development, is truly significant. The phenomenon is the second traffic wave itself, generated by people who are on their way home and who leave their home for the second time, travelling by car in the direction of the city centre to go shopping or do other leisure activities. The third congestion period is also in the afternoon between 15.00 and 19.40, but in the direction of the outskirts (Figure 1). This congestion wave shows the normal vehicular traffic generated by people who leave their workplace to go home.

The second somewhat transient day type, is Friday. On this day, the morning traffic towards the city centre is somewhat lower and shifts slightly later (by 20 minutes). However, the main feature that distinguishes it from other workdays is the earlier start of the afternoon congestion waves in both directions. This wave in the direction of the centre starts from 13.00 and also ends in the evening at 20.20. The main peak of this wave comes 20 minutes earlier than on other workdays. Friday traffic to the outskirts shows a 
similar pattern; it starts also at 13.00 but ends earlier, at 19.40 in the evening, with an earlier peak between 16.40 and 17.20. Thus, we can say that afternoon traffic on Friday has the same volume but has a longer duration than on other workdays. This result indicates that working people probably leave their workplaces earlier on Fridays, and this largely affects the characteristic of urban traffic congestion in our analysed district.

The third separate traffic type is, of course, weekend days. The most important observation about these days is that the volume of traffic over a day is much lower than on the other days of the week (Figure 1). Besides this, we can note that traffic flow patterns are quite similar in both directions. On the weekend days, there are two smaller traffic waves. The first is from 10.20 to 13.40 (mainly to the outskirts), which can refer to the people who leave their home by car to have lunch somewhere. The second, slightly increasing traffic wave is in the afternoon between 16.20 and 20.00 (mainly to the centre). It represents those car users who go to do some leisure activities in the afternoon.

\section{The volume of social time wasted}

Although the costs of traffic jams for citizens are a hot topic among urban researchers, there is no consensus about the real volume of its negative economic impacts (SwEET, M. 2011, 2013). Even so, the volume of wasted time through traffic jams in society can be calculated from collected raw data. If we know the ideal and real travel times and the estimated number of vehicles on particular road sections, the total wasted time in congestion can be determined within the whole district (Table 1).

If we analyse the traffic differences among different days, we can recognize that, while congestion peaks in the direction of the city centre are on Wednesdays, the peak to the outskirts is on Fridays. Thus, the traffic generated by workers travelling by car peaks not on Monday, the first workday, as one would expect, but in the middle of the week. This is generally true for both directions, but on roads

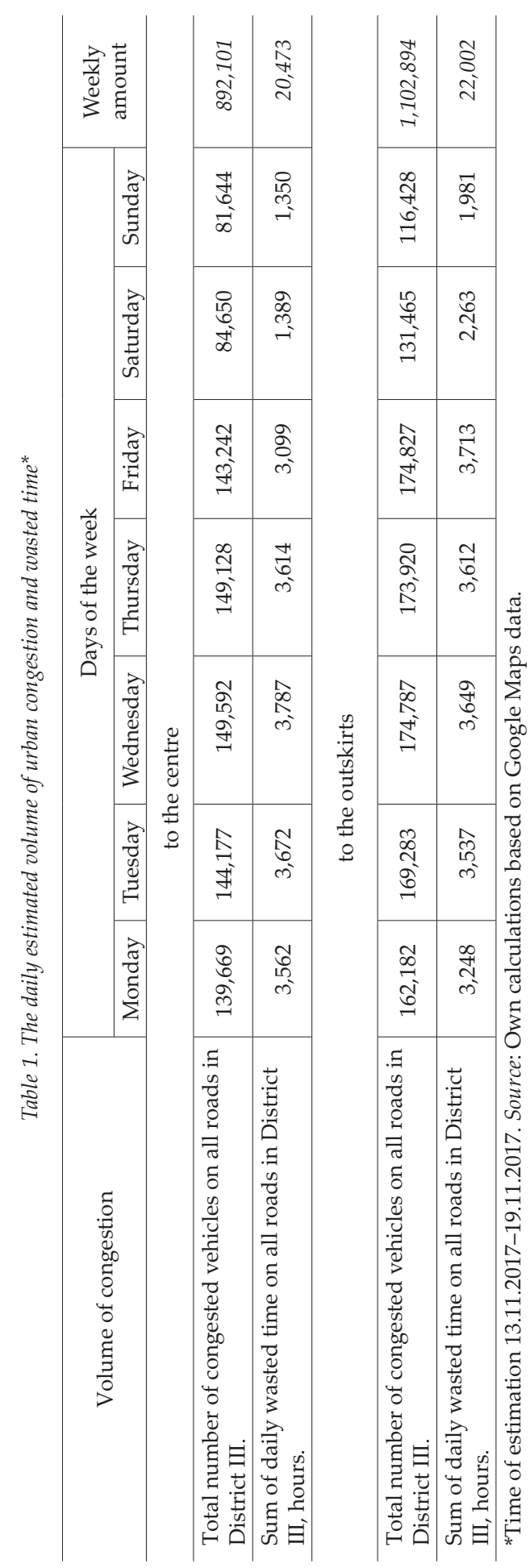


which lead out of the city, this peak remains on Thursday and Friday as well; moreover, the volume of vehicles and wasted time grows slightly. In contrast to workdays, on weekend days, the volume of daily traffic and wasted time is roughly half of the average workday traffic. But there is a larger difference between the two measured directions at weekends. In the direction to the suburban areas, the volume of traffic is higher (by a third) than towards the city centre. It can be related to weekend, holiday and leisure traffic, which starts already on Friday. So, if we see the weekly amount of vehicular traffic, the total number of vehicles in congestion is roughly 200,000 cars higher in the direction of the outskirts or the agglomeration. The origin of this phenomenon is the inclination of citizens to leave their home for leisure activities on weekends.

According to our findings, the magnitude of citizens' wasted time in traffic congestion is so large that it should be a relevant topic for urban planners in the investigated district. If we assume that all cars in congestion have only one passenger (this is the minimum estimation), then, on an ordinary workday, car users waste the total of nearly 300 days within this district alone (Figure 2).

This amount of time is slightly more than a year's worth of full-time work for a citizen, which means that, on a rough estimate, every year, District 3 of Budapest wastes around 250 people's yearly work time because of road traffic congestions. These data should inspire urban planners to explore the features and causes of congestion more intensely, because Budapest in general, and the $3^{\text {rd }}$ district in particular, need to tackle this social and environmental problem.

\section{Congestion hot spots on a deep spatial level}

In the following, four aspects of road traffic patterns are investigated on a fine spatial resolution. The first two answer questions such as how the road size and geographical position relate to the intensity of congestions, or where the traffic hot spots are, and why they

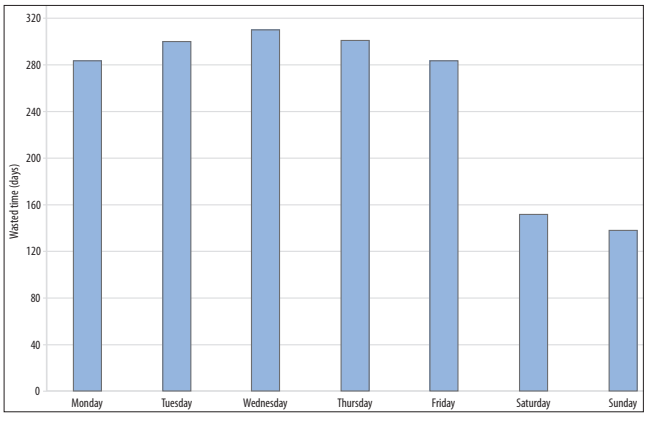

Fig. 2. Sum of daily wasted time in traffic congestion in Budapest's District III, on all roads and in all directions (2017). Time of estimation: 13.11.2017-19.11.2017. Source: Own calculations based on Google Maps data

are there. The third aspect shows the differences between the two measured directions on a deep spatial level. Finally, the last question is whether we can define different road types according to their daily traffic flow.

To unfold the relations between some parameters of road sections and the volume of traffic, Pearson's correlation was calculated (Table 2). The main result of the analysis is that the size of certain roads impacts principally the volume of congestions and social time wasted, but these correlation coefficients are at best medium-strength. The results show that this interdependence is mainly true for workdays, and, in the case of the outskirts' direction, also Fridays and weekend days because of weekend traffic, as mentioned above. There is a weak negative correlation between the distance of road sections from the city centre and the daily amount of congested time wasted. This means that the more centrally located road sections have somewhat higher chance of congestion within a day, mainly on workdays (Table 2).

The last explanatory variable was the geographical position of the road section. This variable was generated with the help of a 2 $\mathrm{km}$ size grid, which was used to define the deeper geographical position of road sections (Figure 3). Although there is a weak positive correlation on workdays and mainly in the 
Table 2. Pearson's correlation coefficients* of road parameters and volume of time wasted

\begin{tabular}{|c|c|c|c|c|}
\hline \multirow{2}{*}{ Explanatory variables } & \multicolumn{4}{|c|}{ Independent variables } \\
\hline & workdays & Friday & Saturday & Sunday \\
\hline \multicolumn{5}{|c|}{ Daily amount of time wasting per $\mathrm{km}$, to the centre, min } \\
\hline Size of road section,total length of lanes, $\mathrm{m}$ & 0.466 & 0.276 & -0.203 & -0.242 \\
\hline Nearest distance from city centre of road section, $m$ & -0.232 & -0.206 & -0.031 & -0.019 \\
\hline Geographical position of the road section, $1 \mathrm{~km}$ grids & 0.153 & 0.151 & 0.043 & 0.057 \\
\hline Geographical position of the road section, $2 \mathrm{~km}$ grids & 0.167 & 0.160 & 0.035 & 0.051 \\
\hline \multicolumn{5}{|c|}{ Daily amount of time wasting per $\mathrm{km}$, to the outskirts, min } \\
\hline Size of road section,total length of lanes, $\mathrm{m}$ & 0.540 & 0.478 & 0.361 & 0.316 \\
\hline Nearest distance from city centre of road section, $m$ & -0.105 & -0.006 & -0.011 & -0.077 \\
\hline Geographical position of the road section, $2 \mathrm{~km}$ grids & 0.031 & -0.055 & -0.020 & 0.055 \\
\hline \multicolumn{5}{|c|}{ Daily amount of time wasting per $\mathrm{km}$, both directions, min } \\
\hline Size of road section,total length of lanes, $\mathrm{m}$ & 0.599 & 0.469 & 0.149 & 0.094 \\
\hline Nearest distance from city centre of road section, $\mathrm{m}$ & -0.215 & -0.135 & -0.024 & -0.064 \\
\hline Geographical position of the road section, $2 \mathrm{~km}$ grids & 0.132 & 0.068 & 0.004 & 0.066 \\
\hline
\end{tabular}

*Highest positive values in italics. Source: Own calculations.

direction of the city centre, the geographical position of these road sections is the weakest explanation for the congestion patterns of our measured district.

Thus, we can say that the congestion volume is primarily connected with the main roads of the district, and because these roads go through the whole area, the other geographical features of road sections are less relevant. It is obvious, that these main roads deserve more attention by urban planners and developers to detect the causes of vehicular traffic jams and decrease them. Another relevant consequence also comes from this observation; namely, the factor of commuting traffic from the agglomeration settlements to Budapest. The two main roads (Numbers 10 and 11) collect all transit traffic from the neighbouring settlements of District 3 and channel it towards the other neighbouring districts of Budapest. Thus, research on the effects of commuter traffic from neighbouring settlements deserve also special attention.

With the help of a database, the daily congestion hot spots are detectable; in other words, we can reveal which road sections have the largest amount of daily congestion and delay time. To measure the inequalities between particular roads, the amount of daily wasted time was used (Figure 4). This indicator shows the permeability of certain roads, and according to the results, there are some roads that are more traffic sensitive than others. In the direction of the city centre three congestion hot spots can be defined. The first is in the southern part of the district, near the downtown area. The main road of a sub-district called Újlak and its quay road integrate the total traffic to the city centre; thus, this is the main congestion hot spot within the district. Connected to this part of the district, there is another important road (Szépvölgyi and Kolostor streets) which channel the complete traffic from the southern highland neighbourhoods to the city centre (Figure 4).

The second, smaller congestion hot spot is the periphery of the Pók Street housing estate, where traffic attempts to avoid the congestion of Main Road 11, however, this itself generates traffic congestion in both directions. The third congestion hot spot is in the northern part of the district, and is affected by the large pre-fab housing estate of Békásmegyer. It is important to see that, although the sum of 


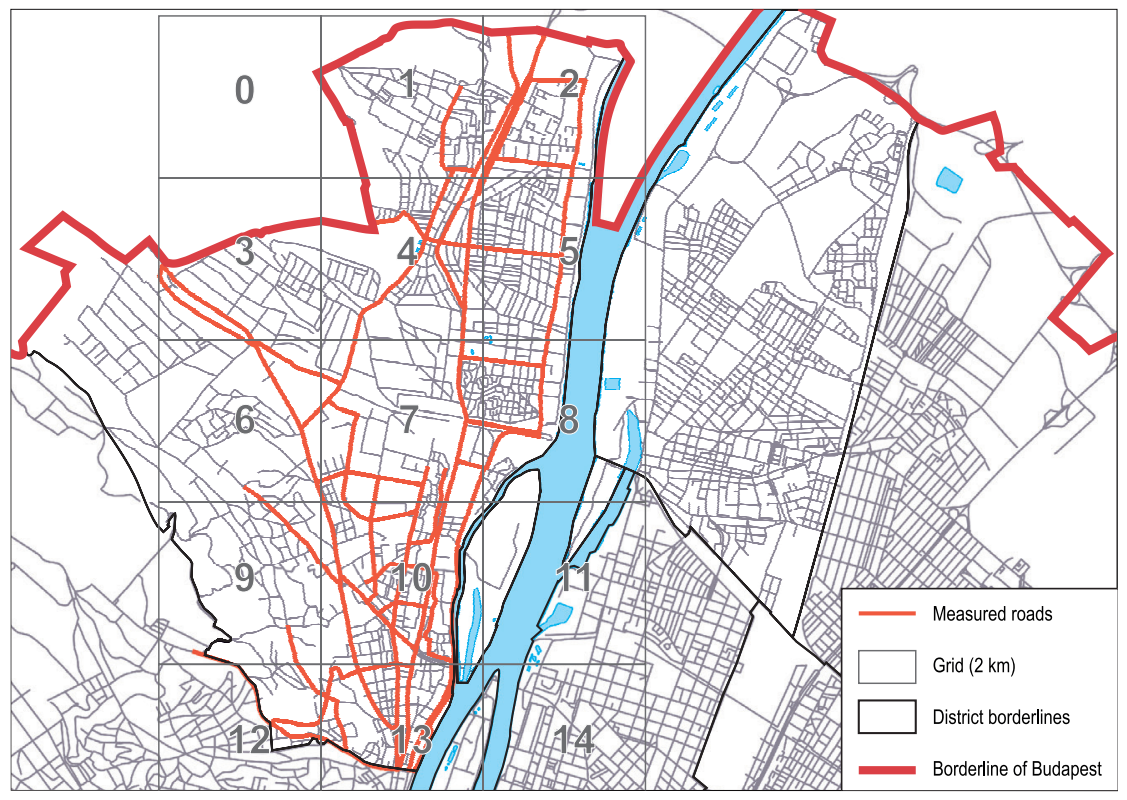

Fig. 3. The $2 \mathrm{~km}$ size grid used to define the geographical positions of road sections (edited by the author)

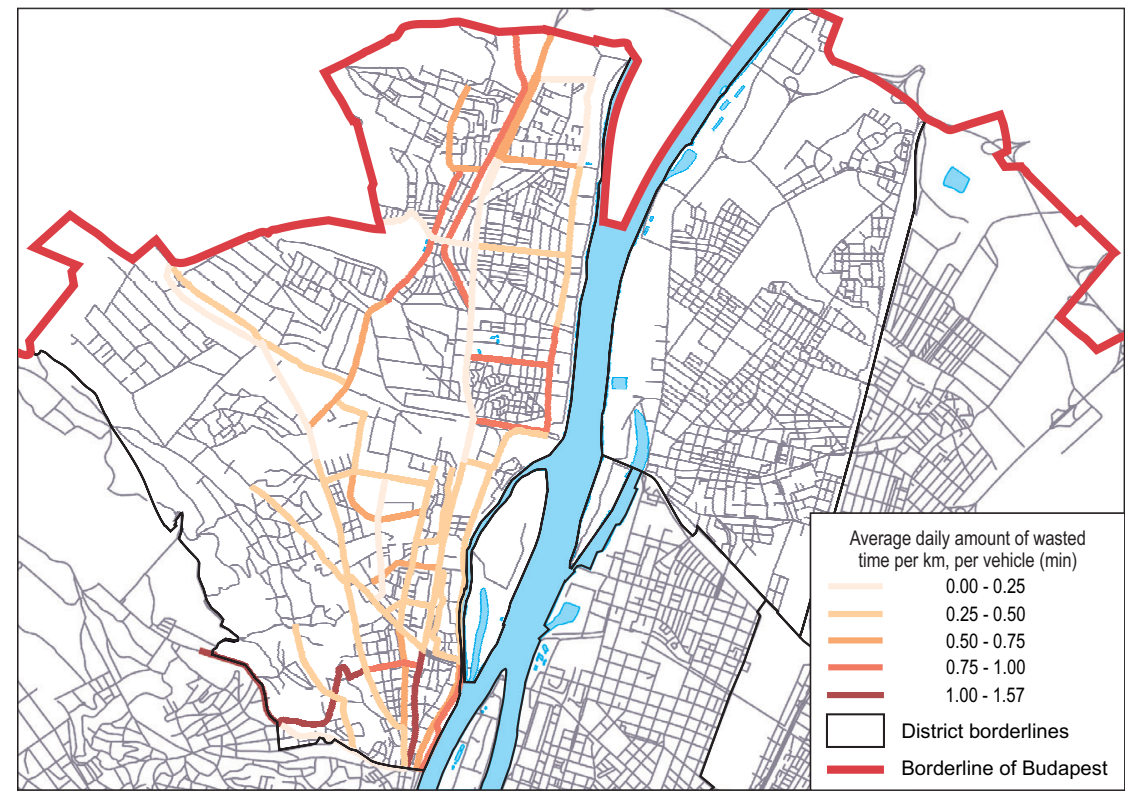

Fig. 4. The average amount of daily wasted time in traffic congestion on different road sections (between Monday and Thursday, towards the city centre). Time of estimation: 13.11.2017-16.11.2017. Source: Own calculations based on Google Maps data 
time wasted is larger on main roads, in this area, the smaller roads are more sensitive to high traffic levels. In addition, the geographical position of the suburban railway can be an explanatory factor, because the railway line lies between Road 11 and congested smaller roads; thus, to reach the main road, drivers must go across the railway. Because of the heavy railway traffic at congestion times, these crossing points frequently slow down vehicular traffic with light barriers. Not counting a couple of smaller road sections, traffic in the direction of the outskirts shows similar patterns to traffic in the direction of the city centre (Figure 5). The three congestion hot spots (mentioned above) are the same within the analysed district.

As the last part of the pilot research one question remained. Can we define road types based on their daily traffic flow? To answer this question, two statistical values were calculated from the daily velocity fluctuation data between 6:00 and 22:00 on all road sections. The first is their standard deviation and the second is their range. Standard deviation can show the volume of daily traffic speed fluctuation on certain roads and range defines the difference between the minimum and maximum values of data series. From these indicators, I calculated a new indicator, which displays the ratio of the standard deviation to the range of the data sets. If this ratio is low, the traffic flow on a certain road is smooth; and if it is higher, the traffic fluctuation within a day is larger. According to this indicator, three road types were separated. For the first type, the indicator was 0 . This means that on type 1 roads the average measured traffic speed is the same within the days. For the second type, the value of the indicator is less than 25 per cent, which shows a medium size traffic fluctuation on a certain road. Type 3 roads have a large daily traffic fluctuation, where the values are between 25 and 50 per cent.

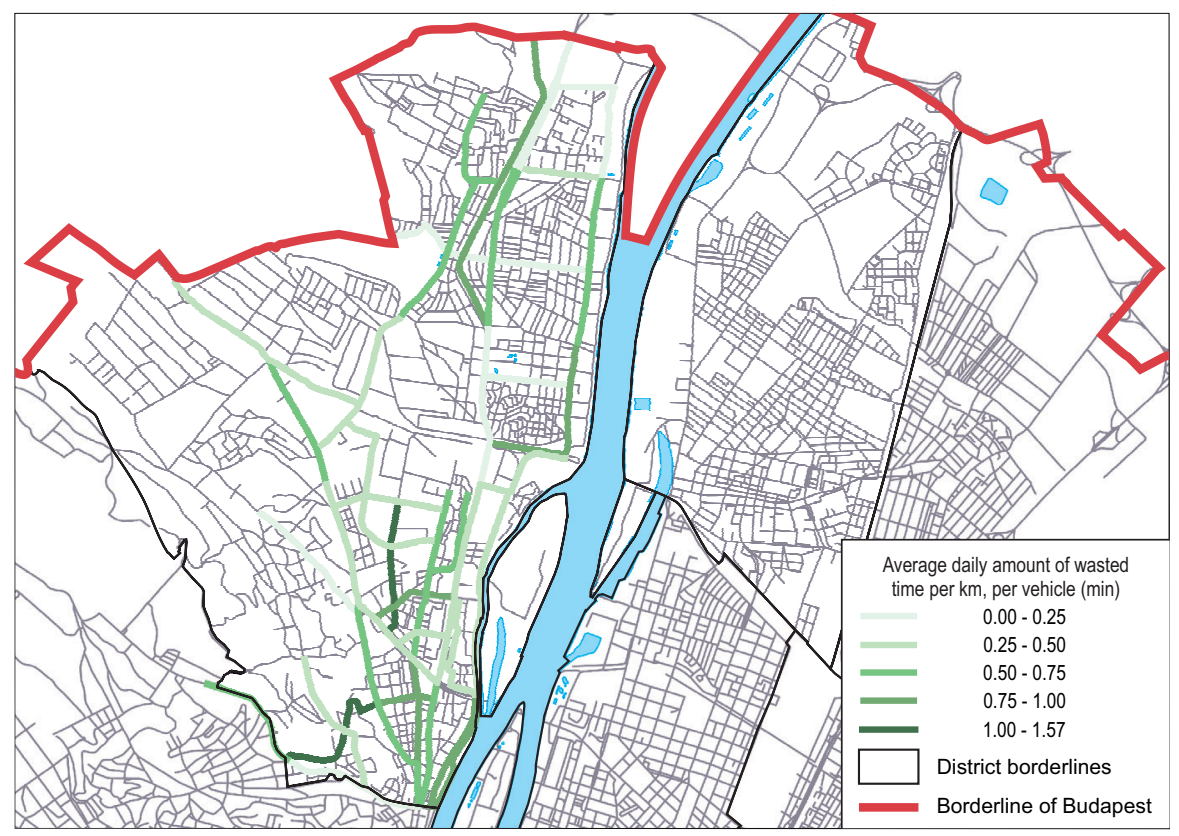

Fig. 5. The average amount of daily wasted time in traffic congestion on different road sections (between Monday and Thursday, to the outskirts) Time of estimation: 13.11.2017-16.11.2017. Source: Own calculations based on Google Maps data 
The analysis of daily flow types focused only on workdays from Monday to Thursday. In general, we can see that road sections that have no traffic fluctuation are the least frequent in both directions. There can be significant traffic on these roads, but their flow is predictable and they have no peaks. These road sections are in the middle of the district and a few of them are in congestion hot spots. In the second type, there are more road sections, and they all have one little congestion peak, which duration is short. In the direction of the centre, this is the morning traffic peak, whereas the formerly mentioned second wave in the afternoon is difficult to perceive. In the direction of the outskirts, road sections also have a small and short instance of congestion, which shows that afternoon traffic, when citizens leave their workplaces, affects these roads very much. Their geographical positions are also interesting, because in this 'medium' type, there are many main road sections and roads that are close to the district or city boundaries. The most peak sensitive type is the third category of roads, and it contains more than half of the investigated roads (Figure 6. and 7).

On these roads, there are two congestion peaks in both directions, but, the morning peak is necessarily stronger in the direction of the city centre, and the afternoon peak is stronger in the direction of the outskirts. These peaks are generally longer and larger than in type 2. Geographically, in the direction of the city centre most of them are smaller roads that are connected to main roads with high traffic, and because their traffic cannot avoid these roads, they have heavier congestion at peak periods (Figure 6). In the other direction, the situation is not the same. Whereas the aforementioned smaller road sections are also congested in the direction of the outskirts, the entire Main Road Number 10 has heavy congestion (Figure 7). The explanation behind these phenomena may be that the northern part of the district (with Road 11) has a larger population density than the western one; thus, while a huge part of traffic from Road 11 probably goes off to these dense neighbourhoods, the larger part of Road 10's traffic goes directly to the settlements of Budapest's agglomeration.

From these results, we can see that there are important differences between road sections by their daily traffic flow. These differences depend on the size and the geographical position of the road section, but the features and morphology of the road system are also important factors. However, equally important finding is that the daily commuting and travelling habits of residents are at least as important factor for comprehending the main road congestion problems, their costs, and their solutions. Traffic peaks are originally generated by society through their driving habits, and these space usage patterns can be changed. This deep spatial analysis can help urban developers to handle urban congestion problems at their basic roots.

\section{Conclusions}

From the analysis of Google Maps data, it can first be concluded that this source of 'big data' is a feasible way of conducting 'smart' scientific research and making smarter development decisions on a city road system. The most relevant advantage of this database is that it is continually generated on a deep spatial and temporal level. Moreover, plenty of cities are measured by Google in the same way; thus, these data are comparable on a wider (even international) level. In Hungary, the forms of 'traditional' annual traffic surveys cannot analyse the patterns of daily traffic flows on a deep spatial level, and local municipalities have also limited capacity to make their own traffic measurements. Hence, using Google Maps data we can extend our knowledge based on traditional census data regarding commuting (e. g. PÁlóczi, G. 2016; VArga, L. et al. 2016).

The second conclusion of this pilot research is that spatial and temporal inequalities are evincible from this database, and heretofore unrecognized processes can be analysed in a deep way, which can help urban planners to smartly rethink their conceptions about 


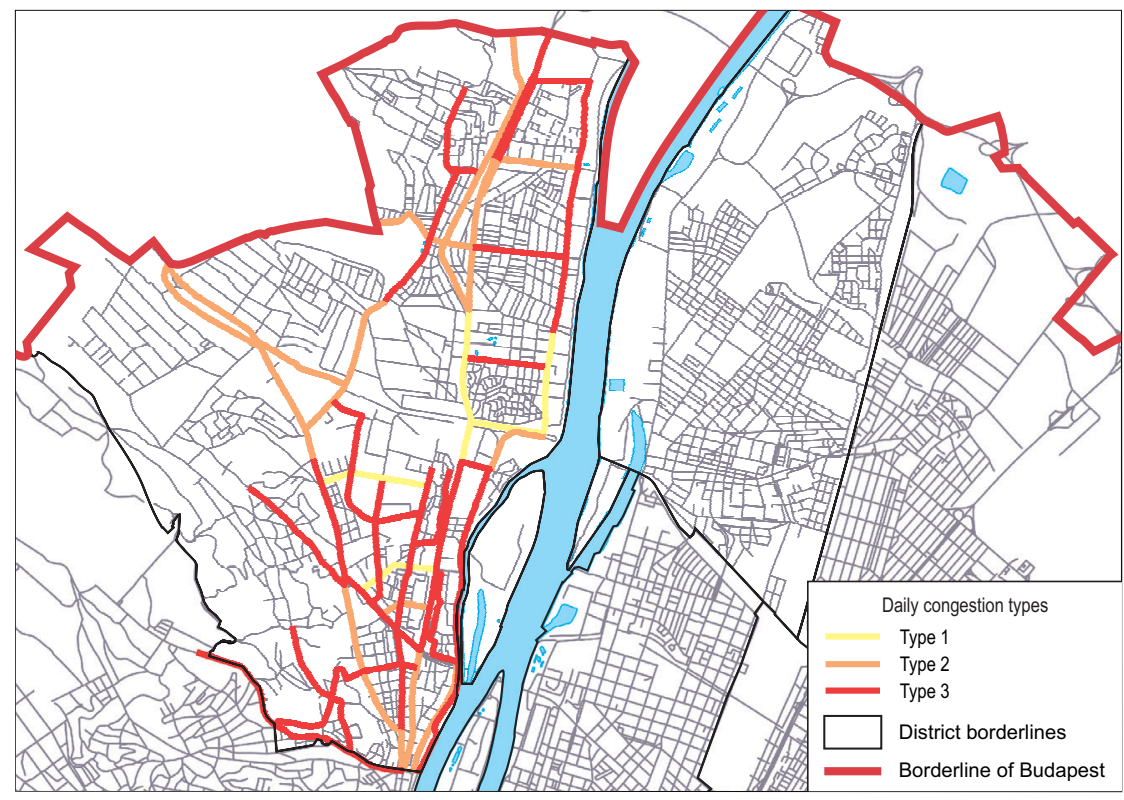

Fig. 6. Types of traffic fluctuation on road sections (between Monday and Thursday, towards the city centre). Time of estimation: 13.11.2017-16.11.2017. Source: Own calculations based on Google Maps data

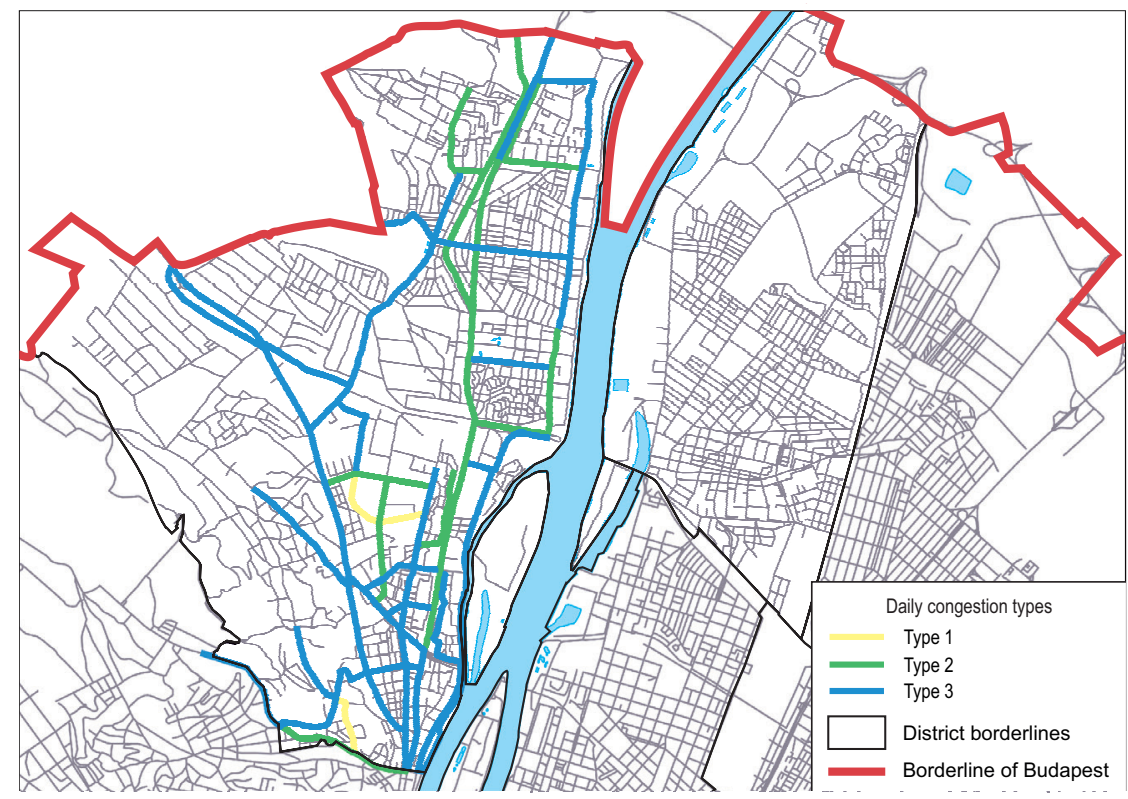

Fig. 7. Types of traffic fluctuation on road sections (between Monday and Thursday, to the outskirts). Time of estimation: 13.11.2017-16.11.2017. Source: Own calculations based on Google Maps data 
the transport system. The research proved empirically that, on workdays, there is a second wave of peak traffic on many roads, and, within our case-study area, there are congestion hot spot times and places. This information can be very useful for residents in planning their travels, and aiming to avoid time-wasting traffic jams.

As the third conclusion, it is important to highlight that Google Maps data have their limits. Firstly, we have to be sensitive with choosing time periods and temporal resolution because some data loss is inevitable. For instance, in this research, the 20-minute periods are useful to estimate traffic and wasted time because the travel time delays cannot be more than 10-12 minutes on roughly one-kmlong road sections. But this is also the weakness of the estimation, because between the two measured time points, some of the traffic data go to waste. Therefore, this research method is highly sensitive in terms of the temporal and spatial resolutions. If the road sections are too long, congested travel times also get higher, but there are limits to the minimum size of road sections and limits to the distance between temporal measured points as well, because the maximum amount of congested travel time on a certain road cannot be higher than the time between measured time points.

The pilot research presented in this paper opens a new perspective for methodology, because it is a useful example of using oftencontested 'big data'. These methodological experiences could provide more input for further research where the database used could be assembled from different Google applications. In the future, it would be important to extend and refine this research in the remaining districts of Budapest or its agglomeration, or even compare the result with the vehicular traffic patterns of other cities.

\section{REFERENCES}

Abella-García, A., Ortiz-de-Urbina-Criado, M. and De-Pablos-Heredero, C. 2015. The ecosystem of services around smart cities: An exploratory analysis. Procedia Computer Science 64. 1075-1080.
Al Nuaimi, E., Neyadi, H.A., Mohamed, N. and AlJARoodi, J. 2015. Applications of big data to smart cities. Journal of Internet Services and Applications 6. (1): 1-15.

Antтiroiko, A.V. 2013. U-cities reshaping our future: reflections on ubiquitous infrastructure as an enabler of smart urban development. AI \& SOCIETY Journal of Knowledge, Culture and Communication 28. (4): 491-507.

Anttiroiko, A.V., Valkama, P. and Bailey, S.J. 2014. Smart cities in the new service economy: building platforms for smart services. AI \& SOCIETY Journal of Knowledge, Culture and Communication 29. (3): 323-334.

Bálint, D. and Trócsányi, A. 2016. New ways of mobility: the birth of ridesharing. A case study form Hungary. Hungarian Geographical Bulletin 65 (4): 391-405.

Batty, M., Axhausen, K.W., Giannotti, F., Pozdnoukhov, A., Bazzani, A., Wachowicz, M., Ouzounis, G. and Portugali, Y. 2012. Smart cities of the future. The European Physical Journal Special Topics 214. 481-518.

Camagni, R., Gibelli, M.C. and Rigamonti, P. 2002. Urban mobility and urban form: the social and environmental costs of different patterns of urban expansion. Ecological Economics 40. (2): 199-216.

Chin, A.T.H. 1996. Containing air pollution and traffic congestion: Transport policy and the environment in Singapore. Atmospheric Environment 30. (5): 787-801.

Chuan TaO, Y., Zhang, X., Hui, C., JingYuan, W., Daven, C. and Bertrand, D. 2015. A literature survey on smart cities. Science China Information Sciences 58. (10): 1-18.

Cohen, H. and Southworth, F. 1999. On the measurement and valuation of travel time variability due to incidents on freeways. Journal of Transportation and Statistics 2. (2): 123-131.

Downs, A. 1992. Stuck in Traffic. Washington, Brookings Institution.

ERHART, Sz. 2007. A budapesti közlekedési dugók okai és következményei (The causes and consequences of traffic jams in Budapest). Közgazdasági Szemle 54. (5): 435-458.

Fleischer, T. and Tir, M. 2016. The transport in our time-budget. Regional Statistics 6. (2): 54-94.

Giffinger, R., Fertner, C., Kramar, H., Meijers, E. and Pichler-Milanovic, N. 2007. Smart cities: Ranking of European medium-sized cities. Vienna, Vienna University of Technology.

Graham, S. 1997. Telecommunications and the future of cities: de-buking the myths. Cities 14. (1): 21-29.

Greenshields, B.D. 1935. A Study of Traffic Capacity. Highway Research Board Proceedings 14. 448-477.

Keserú, I. 2013. Commuting patterns of secondary school students in the functional urban region of 
Budaepst. Hungarian Geographical Bulletin 62. (2): 197-219.

Kitchin, R. 2013. Big data and human geography: Opportunities, challenges and risks. Dialogues in Human Geography 3. (3): 262-267.

KITchin, R. 2014. The real-time city? Big data and smart urbanism. GeoJournal 79. (1): 1-14.

Leduc, G. 2008. Road Traffic Data: Collection Methods and Applications. Working Papers on Energy, Transport and Climate Change N. 1, European Commission - Joint Research Centre, Institute for Prospective Technological Studies, $53 \mathrm{p}$.

Lengyel, B. and Jakobi, Á. 2016. Online social networks, location, and the dual effect of distance from the centre. Tijdschrift Voor Economische en Sociale Geografie 107. (3): 298-315.

Magyar Közút Nonprofit Zrt. 2017. Az országos közutak 2016. évre vonatkozó keresztmetszeti forgalma (Crosssection traffic of public roads in Hungary for 2016). Budapest, One Planet Mérnökiroda Kft.

Manyika, J., Chiu, M., Brown, B., Bughin, J., Dobbs, R., RoXBurgh, C. and Byers, A.H. 2011. Big data: The next frontier for innovation, competition, and productivity. McKinsey Global Institute.

Marvin, S.J. 1994. Green signals. The environmental role of telecommunications in cities. Cities 11. (5). 325-331.

Mattoni, B., Gugliermetti, F. and Bisegna, F. 2015. A multilevel method to assess and design the renovation and integration of Smart Cities. Sustainable Cities and Society 15. 105-119.

Morgul, E., Yang, H., Kurkcu, A., Ozbay, K., Bartin, B., Kamga, C. and Salloum, R. 2014. Virtual sensors: Web-based real-time data collection methodology for transportation operation performance analysis. Transportation Research Record: Journal of the Transportation Research Board 2442. (12): 106-116.

Navarro, C., Roca-Riu, M., Furió, S. and Estrada, M. 2015. Designing new models for energy efficiency in urban freight transport for smart cities and its application to the Spanish case. Transportation Research Procedia 12. 314-324.

Neirotti, P., De Marco, A., Cagliano, A.C., Mangano, G. and Scorrano, F. 2014. Current trends in Smart City initiatives: Some stylised facts. Cities 38. 25-36.

NiARos, V. 2016. Introduction a Taxonomy of the "Smart City": Towards a Commons-Oriented Approach? tripleC: Communication, Capitalism \& Critique 14. (1): 51-61.

PÁLóczI, G. 2016. Researching commuting to work using the methods of complex network analysis. Regional Statistics 6. (1): 3-22.
Qingyu, L., Zhicai, J., Baofeng, S. and Hongfei, J. 2007. Method Research on Measuring the External Costs of Urban Traffic Congestion. Journal of Transportation Systems Engineering and Information Technology 7. (5): 9-12.

RIAL, N. 2013. The power of big data in Europe. New Europe, May 24 ${ }^{\text {th }}$. https://www.neweurope.eu/ article/power-big-data-europe/ Downloaded: 28.02.2017.

Rouwendal, J. and Nijkamp, P. 2004. Living in two worlds: A review of home-to-work decisions. Growth and Change 35. (3): 287-303.

Schrank, D., Lomax, T., Turner, S., Geng, L., Li, Y. and Koncz, N. 2010. TTI's 2010 Urban Mobility Report. Texas Transportation Institute, A\&M University, College Station TX.

Smolan, R. and Erwitt, J. 2012. The Human Face of Big Data. New York, Sterling.

Steenbruggen, J., Tranos, E. and Nijkamp, P. 2015. Data from mobile phone operators: A tool for smarter cities? Telecommunications Policy 39. (3-4): 335-346.

STOPHER, P.R. 2004. Reducing road congestion: A reality check. Transport Policy 11. (2): 117-131.

SweEt, M. 2011. Does Traffic Congestion Slow the Economy? Journal of Planning Literature 26. (4): 391-404.

Sweet, M. 2013. Traffic Congestion's Economic Impacts: Evidence from US Metropolitan Regions. Urban Studies 51. (10): 2088-2110.

Townsend, A.M. 2013. Smart Cities. Big data, civic hackers, and the quest for a new utopia. New York, W.W. Norton \& Company.

VArGa, L., Tóth, G. and NéDA, Z. 2016. An improved radiation model and its applicability for understanding commuting patterns in Hungary. Regional Statistics 6. (2): 27-38.

Wardrop, J.G. and Charlesworth, G. 1954. A method of estimating speed and flow of traffic from moving vehicle. Proceeding of the Institution of Civil Engineers 3. (1): 158-171.

Zikopoulos, P.C., Eaton, C., de Roos, D., Deutsch, T. and LAPIs, G. 2012. Understanding big data. New York, McGraw Hill.

http://gadgets.ndtv.com/apps/features/how-googlemaps-gets-its-remarkably-accurate-real-timetraffic-data-1665385

http://trrjournalonline.trb.org/doi/pdf/10.3141/2442-12 